\title{
Modelagem de Sistemas Ambientais Usando o Software Stella
}

\author{
Alcides de C. Amorim Neto \\ Jean Antunes C. da Costa* \\ Universidade do Estado do Amazonas - Departamento de Matemática, UEA \\ 69050-010, Escola Normal Superior, Manaus, AM \\ E-mail: dooham2007@gmail.com ; jean.antunes@live.com
}

\begin{abstract}
RESUMO
O uso de modelagem matemática para simulação de sistemas ambientais proporciona um tratamento realístico das interações ocorridas nesses conjuntos. Porém, para obter resultados que representem de forma satisfatória tais modelos, faz-se necessário o uso de ferramentas matemáticas mais robustas, como as equações diferenciais ordinárias que podem ser implementadas em softwares específicos para esse tipo de estudo, tendo em vista que nem sempre a solução analítica é possível para a resolução de certos problemas. O software de modelagem Stella possibilita a realização dessas implementações para simular cenários futuros e pareceres do ponto de vista de previsibilidade.

Nosso objetivo é mostrar o uso do software Stella para a realização de simulações usando equações diferenciais para representar modelos populacionais e assim interpretar os resultados obtidos através de saídas gráficas e em tabelas.

A primeira etapa do projeto consiste no estudo de equações diferenciais exponenciais, através de suas respectivas soluções analíticas e em seguida, as mesmas são implementadas no software Stella e comparadas. Essas equações servirão para a criação de modelos ambientais práticos.

A partir dos objetivos e do planejamento traçado, acredita-se que a Equação Diferencial Exponencial foi implementada com sucesso no software Stella 8 e pode ser usada na simulação de crescimento e decrescimento populacional com dados iniciais fictícios e reais como, por exemplo, a estimativa da população para a cidade de Manaus para o ano de 2020, bem como a plotagem e análise gráfica. Outro exemplo de dinâmica populacional que também pode ser implementada no Stella é o modelo Presa-Predador de lotka-volterra. O modelo de produtividade dos ecossistemas, Ciclo do Carbono, o tempo de residência da Biomassa de folhas, galhos e raízes em florestas e campos, e Sistemas Climáticos e Hidrológicos também podem ser simulados em trabalhos futuros através do Stella.
\end{abstract}

Palavras-chave: Modelagem Matemática, Matemática Computacional, Soluções Numéricas

\section{Referências}

[1] R. C. Bassanezi. Ensino-aprendizagem com modelagem matemática. 3.ed. São Paulo: Contexto, 2009.

[2] A. Christofoletti. Modelagem de Sistemas Ambientais. 1 ${ }^{a}$ ed. São Paulo: Edgard Blücher, 1999.

[3] A. C. Z. de Souza, C. A. M. Pinheiro. Introdução à Modelagem, Análise e Simulação de Sistemas Dinâmicos. Rio de Janeiro: Interciência, 2008.

[4] D. G. Zill. Equações Diferenciais com Aplicação em Modelagem. Thomsom learning, 2003. 